\title{
Reproductive success in the European shag is linked to annual variation in diet and foraging trip metrics
}

\author{
Svein-Håkon Lorentsen ${ }^{1, *}$, Jenny Mattisson ${ }^{1}$, Signe Christensen-Dalsgaard ${ }^{1,2}$ \\ ${ }^{1}$ Norwegian Institute for Nature Research, 7485 Trondheim, Norway \\ ${ }^{2}$ Department of Biology, Norwegian University of Science and Technology (NTNU), 7491 Trondheim, Norway
}

\begin{abstract}
Seabird populations have declined worldwide, and several of the potential threats are of anthropogenic origin. To understand how changes in seabird populations relate to environmental conditions it is important to know the functional relationships between prey availability and foraging behaviour, prey choice and breeding performance over several years. This was studied by linking breeding success of European shag Phalacrocorax aristotelis to variation in diet composition, and investigating the underlaying mechanism driving this variation, primarily based on behavioural costs associated with foraging, such as foraging range and diving effort. We obtained demographic data and foraging trip metrics (using GPS-loggers and time-depth recorders) from a shag colony at Sklinna, Central Norway, during the 2011-2016 breeding seasons. Breeding population size was closely and positively correlated with breeding success, which in turn was positively correlated with the proportion of saithe Pollachius virens in the diet. When the dietary proportion of uncommon prey species increased, breeding success decreased. Breeding success was negatively influenced by increasing distance travelled and accumulated dive depths on an annual basis. Summed dive depths were greatest when prey species other than saithe dominated the diet. We found that in years with low availability of saithe fewer shags bred, and those that did had lower breeding success. This indicates that in years with poor feeding conditions, there might not be sufficient resources in the foraging area to support the whole breeding population of shags.
\end{abstract}

KEY WORDS: Phalacrocorax aristotelis $\cdot$ Seabird diet $\cdot$ Saithe $\cdot$ Pollachius virens $\cdot$ Foraging range Trip length $\cdot$ Dive depth

\section{INTRODUCTION}

Worldwide, many seabird populations have declined dramatically with some of the suggested threats being climate-related changes in marine ecosystems, competition with commercial fisheries, coastal development and invasive predators (e.g. Halpern et al. 2009, Croxall et al. 2012, Lewison et al. 2012). These threats may have profound effects throughout entire food webs from primary producers to top predators, thus affecting seabird populations (e.g. Poloczanska et al. 2013). For instance, in the North Sea, climate-related changes in abundance

${ }^{*}$ Corresponding author: shl@nina.no and distribution of the copepod Calanus finmarchicus, an important food source for small forage fish, was found to negatively affect breeding success of 3 common piscivorous seabirds (Frederiksen et al. 2013). This was not the case for a colony situated farther north in the Norwegian Sea, suggesting that the predicted northwards decline in copepod abundance might only have influenced the southernmost colonies so far (Frederiksen et al. 2013).

Seabirds are conspicuous top predators in marine ecosystems. The main diet of many seabird species is small fish or young age-classes of larger fish that feed on copepods (e.g. Shealer 2002). During the breeding

() The authors 2019. Open Access under Creative Commons by Attribution Licence. Use, distribution and reproduction are unrestricted. Authors and original publication must be credited. 
season, seabird foraging ranges are limited by the need to return to the colonies at regular intervals to provision the brood, cf. Orians \& Pearson (1979). Thus, seabird foraging ranges are determined by the bird's flight capabilities, food availability within the foraging range and the frequency with which they must return to the breeding sites. Many seabird species breed in dense colonies and display densitydependent responses to changes in prey availability (e.g. Ashbrook et al. 2010). Marine ecosystems are dynamic with high spatio-temporal variability in prey availability. These short- and long-term variations in the abundance of prey species require flexibility in foraging behaviour and choice of diet in seabirds (e.g. Hamer et al. 2007, Garthe et al. 2011, Pettex et al. 2012, Christensen-Dalsgaard et al. 2018). Seabirds can compensate for low availability of prey around the colony by intensifying their search effort on foraging grounds and/or by increasing their foraging range (e.g. Burke \& Davoren 2009, Ponchon et al. 2014). However, as central place foragers, their time and effort at sea often remain constrained by the need to return regularly to the colony. Alternatively, the birds can decide to skip breeding, determining the relation between breeding success and breeding numbers.

The diet composition of seabirds in many colonies has changed during recent decades, following changes in the distribution and populations of targeted fish populations (e.g. Anker-Nilssen \& Aarvak 2006, Pichegru et al. 2007, Howells et al. 2017). This has had profound effects on the foraging behaviour for some populations (e.g. Pichegru et al. 2007). In northern gannets Morus bassanus, durations of foraging trips increase when food availability is reduced (e.g. Hamer et al. 1993, Lewis et al. 2006, Hamer at al. 2007, Pettex et al. 2012), and tend to increase with the size of the colony (e.g. Lewis et al. 2001). This indicates that when many birds breed simultaneously in one colony, density-dependent depletion of food resources may occur (cf. Ashmole's halo; Ashmole 1963, e.g. Lewis et al. 2001, Elliott et al. 2009). Similar links between colony size, foraging distances and environmental conditions have also been demonstrated for other seabird species including cape gannets M. capensis, Manx shearwaters Puffinus puffinus and European shag Phalacrocorax aristotelis (hereafter shag, e.g. Riou et al. 2011, Davies et al. 2013, Bogdanova et al. 2014). For instance, Bogdanova et al. (2014) showed that foraging ranges in shags increased with breeding population size when breeding success was low, potentially caused by a density-dependent effect if local prey was depleted.
However, although diet composition (annual proportion of lesser sandeel Ammodytes marinus) varied over the $15 \mathrm{yr}$ studied, this had no impact on the foraging range, indicating that the total quantity of available fish around the colony might be more important than species composition.

To understand how changes in seabird populations relate to environmental conditions, and to predict how they will respond to future changes in marine ecosystems, a detailed understanding of the functional relationships between prey availability and seabird foraging behaviour, prey choice and breeding performance is needed. To achieve this, it is pivotal to understand the interplay between environmental conditions and intrinsic mechanisms, e.g. density dependence (e.g. Quintana et al. 2011) in a population's foraging distribution over many years (e.g. Bogdanova et al. 2014). Therefore, in this study, our aim was to explore how long-term variation in foraging effort, breeding success and breeding numbers is influenced by prey composition in the diet of a coastal seabird, the shag. Since 2011, shag diet, reproductive success and population size has been monitored at Sklinna, an island colony off Central Norway, concurrently with tracking of their foraging behaviour using miniaturised GPS-loggers and time-depth recorders (TDRs). Previous work at Sklinna has revealed the shag's dependency on saithe Pollachius virens as the primary prey (Hillersøy \& Lorentsen 2012). Furthermore, Bustnes et al. (2013) and Lorentsen et al. (2015) demonstrated a clear relationship between the proportion of primarily $1 \mathrm{yr}$ old saithe in their diet and timing of breeding and breeding success. In this study, we focused on the following research questions: (1) How is breeding success and population size related to annual variation in diet composition, i.e. does low proportion of the preferred prey (saithe), negatively affect the breeding success and/or the number of birds breeding? (2) How is shag foraging effort, described by specific trip metrics (foraging range, diving effort), related to prey species? (3) How is the variation in foraging effort related to breeding success in a given year, i.e. does increased foraging effort result in lower breeding success?

\section{MATERIALS AND METHODS}

\subsection{Study animals, study site, and field procedures}

Shags are nearshore-foraging, pursuit-diving seabirds that breed throughout the Northeast Atlantic (Cramp \& Simmons 1977). Shags are sexually dimor- 
phic, with males being about 15\% heavier than females (Wanless \& Harris 1997).

The study was carried out in a shag colony at the islands of Sklinna $\left(65^{\circ} 12^{\prime} \mathrm{N}, 10^{\circ} 59^{\prime} \mathrm{E}\right)$, off Central Norway (Fig. 1). The field period was from late May or early June to mid-July in 2011-2016. Annual data on shag breeding population size (apparently occupied nests within the whole colony) was collected using standardised methods (cf. Walsh et al. 1995).

Annual breeding success was assessed from control nests $(\bar{x} \pm \mathrm{SD}=52 \pm 1.6$, range $=50-54)$ checked every $5^{\text {th }}$ day during the annual study periods. The control nests were located in the same part of the colony each year. As fieldwork was terminated at the same date each year, breeding success was defined as the number of chicks $>20 \mathrm{~d}$ of age per nest rather than the number of fledged chicks per nest, to include years with late hatching.

\subsection{Diet data}

Regurgitated pellets, containing undigested fish remains such as otoliths and bone fragments, were collected within periods of $5 \mathrm{~d}$ throughout the entire field period. We restricted the number of pellets

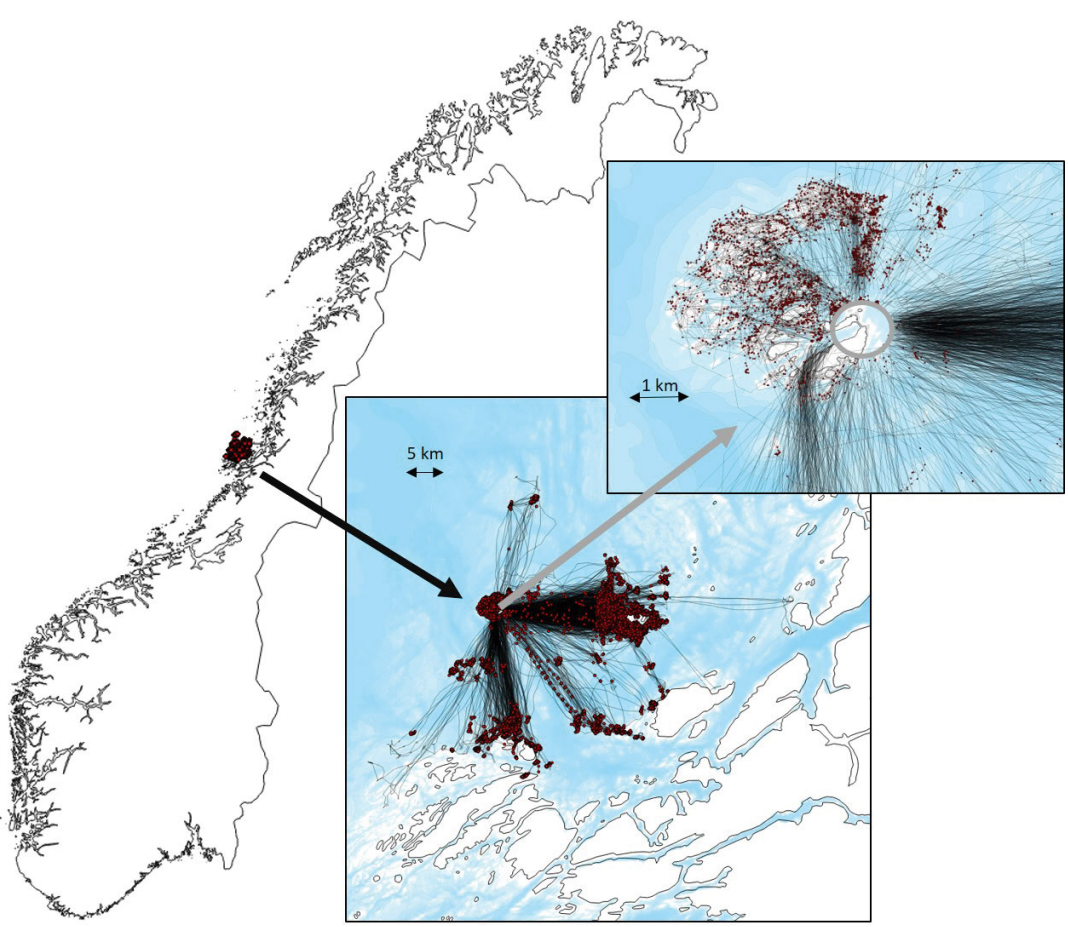

Fig. 1. Location of Sklinna in Norway with an insert zooming around the European shag colony. Black lines: trips; dots: dive locations. Note that not all trips have dive data. Grey circle: $500 \mathrm{~m}$ buffer around the colony in which data was excluded from the trips (Text S1 \& Fig. S1 in the Supplement at www.intres.com/articles/suppl/m619p137_supp.pdf) collected within each $5 \mathrm{~d}$ period to $20-25$ due to analytical capacities. All pellets were collected within the same part of the colony as both control nests and nests used for GPS- and TDR-data collection (see below). Between 130-228 pellets were collected annually $(\bar{x} \pm \mathrm{SD}=172 \pm 47$, total $=1034)$. Pellet analysis was conducted following Hillersøy \& Lorentsen (2012). To estimate diet composition, fish otoliths were sorted in pairs based on size, matching appearance and/or extent of erosion (wear) and identified to the lowest possible taxonomic level using Härkönen (1986) and a reference collection. Individual fish body mass was calculated using otolith length or width, and the equations provided by Jobling \& Breiby (1986) and Härkönen (1986). Quantifying diet from pellets has some limitations which must be considered when calculating prey biomass (see e.g. Lorentsen et al. 2018).

Saithe, mainly 0 and $1 \mathrm{yr}$ old fish, but sometimes also 2 yr old fish, is the most common prey caught by shags at Sklinna, followed by cod Gadus morhua and poor cod Trisopterus minutus (Hillersøy \& Lorentsen 2012, Bustnes et al. 2013, Lorentsen et al. 2015). Thus, in this study, prey species were categorized into 5 groups: 0, 1 and 2 yr old saithe, other gadids (cod and poor cod) and other fish species (termed 'other fish prey').

Diet composition was estimated following Michelot et al. (2017). First, we calculated the proportion of each prey group by biomass in each pellet (biomass of a prey group in a pellet / total biomass in the same pellet). Then we summed the proportions of biomass of each prey group per year, and per $5 \mathrm{~d}$ period within a year, and re-transformed the sums to represent proportions $(0-1)$ of each prey group. Yearly proportions were used in the analyses of breeding success and the proportion in each $5 \mathrm{~d}$ period was used in the trip analyses (see below).

Shags at Sklinna adjust their timing of breeding according to the occurrence of saithe in their diet, especially the 1 yr old category (Lorentsen et al. 2015). To account for potential changes in the shags' prey preferences and foraging behaviour with breeding stage, prior to data analyses, we adjusted the $5 \mathrm{~d}$ periods in which food samples were collected. In that way, the $5 \mathrm{~d}$ period in which the median date of hatching occurred 
was termed period 0 , and the subsequent $5 \mathrm{~d}$ periods were re-numbered according to this.

\subsection{GPS and TDR data collection}

Breeding shags, opportunistically selected within the same part of the colony as the control nests, were caught at the nest by hand or with a noose pole. Attempts were made to capture an equal number of males and females. Sex of the adults was determined by size and vocalization (cf. Cramp \& Simmons 1977). The adult shags were instrumented with GPS-loggers (in 2011 Earth and Ocean mGPS-2, otherwise i-gotU GT-120, Mobile Action Technology, re-fitted in heat shrink tubes) or a combination of GPS-loggers and TDR-loggers (G5, CEFAS Technology). The GPSloggers were attached to 3-4 middle tail feathers using strips of TESA ${ }^{\circledR}$ tape. TDR-loggers were either attached to the GPS-logger prior to instrumentation or to the feathers on the back of the bird (some individuals in 2011) using TESA ${ }^{\circledR}$ tape. The maximum weight of the deployment when using both GPS- and TDR-loggers was $30.6 \mathrm{~g}$, corresponding to 1.6 and $1.8 \%$ of mean body mass of males and females at Sklinna, respectively. As diving seabirds have been shown to experience high energetic costs with any increase in device mass (Vandenabeele et al. 2012), the size of the loggers was kept as low as possible. The loggers were removed after approximately $3 \mathrm{~d}$. Deployment of loggers normally required less than $3 \mathrm{~min}$ of handling and retrieval less than $10 \mathrm{~min}$. Birds were fitted with loggers during late incubation (8\% of captures) and throughout the chick-rearing period (June-July) until chicks were up to approximately $35 \mathrm{~d}$ old $(\bar{x} \pm \mathrm{SD}=11 \pm 7.0 \mathrm{~d}$, range $=0-35 \mathrm{~d})$. Chick age was determined using morphological criteria experienced from the control nests checked every $5^{\text {th }}$ day. During the study period, 134 birds were instrumented with GPS-loggers only and 274 with a combination of GPS- and TDR-loggers, of which $105(78 \%)$ and $203(74 \%)$, respectively, were retrieved. Of the loggers deployed, $8.3 \%$ failed during deployment. Of the loggers not retrieved, 55.5\% were due to the bird losing the logger, $13.9 \%$ of the nests were depredated during the instrumented period, $2.8 \%$ of the nests failed (the chicks died during the instrumented period) and $1.4 \%$ of the birds could not be re-trapped. For $26.4 \%$ of the loggers not retrieved, we lack information about the birds' fate. For cleaning and preparation of logger data, see Text S1, Figs. S1 \& S2 in the Supplement at www.intres.com/articles/suppl/m619p137_supp.pdf.
The total distance travelled during a trip ('trip distance') was calculated as the sum of all step lengths (i.e. the straight distances in meters between subsequent locations) outside a $500 \mathrm{~m}$ buffer around the colony (Text S1) and the straight distance from the colony to the first and the last location in the trip. By doing this, we removed possible non-straight movements close to the colony before and after foraging trips. Trip duration was calculated as the time between the first and the last location of the trip plus the estimated time for flying directly to and from the first and last location and the colony. The latter was estimated using the distance to the colony and the average $( \pm \mathrm{SE})$ flight speed for inbound and outbound flights $\left(11.6 \pm 0.04 \mathrm{~m} \mathrm{~s}^{-1}\right)$ based on a subset of the data that had been visually classified as flying (53 293 step lengths). Dives were assigned to a trip based on date and time (i.e. all dives that occurred between the first and last GPS location of the trip were included in that trip), and the total number of dives, total dive time (i.e. the sum of all individual dive times) and total dive depth (i.e. the sum of all individual dive depths) was summarized for each trip.

Each trip was subsequently related to the estimated diet of the population during the $5 \mathrm{~d}$ period in which it occurred. This was based on the assumption that the diet from collected pellets were representative for the trips conducted in the same period (cf. Bogdanova et al. 2014). This is justified by the close proximity of the control nests (i.e. the nests of the instrumented birds) and the area where the shag pellets were collected, which were all situated within a circle with a $\sim 150 \mathrm{~m}$ radius. To further make this an acceptable assumption we used main diet instead of proportion of prey groups. If a single prey group exceeded $40 \%$, this group was assigned as main diet ( 2 prey groups $>40 \%$ never occurred); if no group exceeded $40 \%$ main diet was assigned as 'mixed diet'.

\subsection{Data analysis}

When analysing the effect of diet on foraging trip metrics we only used the 2 response variables that we assumed to be most representative of the costs associated with foraging, i.e. trip distance $\left(\mathrm{n}_{\text {trips }}=\right.$ 865) and total dive depth (i.e. the sum of all maximum dive depths within a trip, $\mathrm{n}_{\text {trips }}=563$ ). The variables chosen will also indirectly represent some of the other non-chosen measured trip variables. For example, trip distance was highly correlated with the maximum straight distance between the colony and the furthest GPS-location $\left(\mathrm{R}^{2}=0.97\right)$ and total dive depth 
with total dive duration $\left(R^{2}=0.92\right)$. Trip duration was also correlated to some degree with both trip distance $\left(R^{2}=0.65\right)$ and total dive depth $\left(R^{2}=0.57\right)$, but less strongly. Trip metrics were analysed using linear mixed models in R (R Development Core Team 2016) with library 'Ime4' (Bates et al. 2015) where main diet, year, parental sex and age of the chicks were included as explanatory variables and individual bird as a random intercept. Sex was included in the analysis as there are sexual differences in foraging behavior of shags at Sklinna (Christensen-Dalsgaard et al. 2017). Year was included as a fixed effect to account for other unmeasured, but potentially influential, inter-annual variables such as prey availability. Model performance was evaluated based on Akaike's information criterion (AIC) values (Burnham \& Anderson 2002). Conditional and marginal $\mathrm{R}^{2}$ values were estimated for the top ranked models (library 'MuMin'; Barton 2016) and the factor levels were compared by obtaining their least-square means (library 'lsmeans'; Lenth 2016).

To assess if breeding success was related to population size, diet or foraging activity, we used simple linear regression models in R. As we only had 6 yr of data, we could not combine several variables in the same model without overparameterizing. Diet was included as annual proportions of each prey group. Because of the rare occurrence of the prey group '2 yr old saithe', this was excluded as a single variable in these analyses but combined with 0 and $1 \mathrm{yr}$ old saithe into a new prey group called 'total saithe'. The explanatory variable 'foraging activity' included in the model above was estimated as annual mean values of trip distance and total dive depth using 2

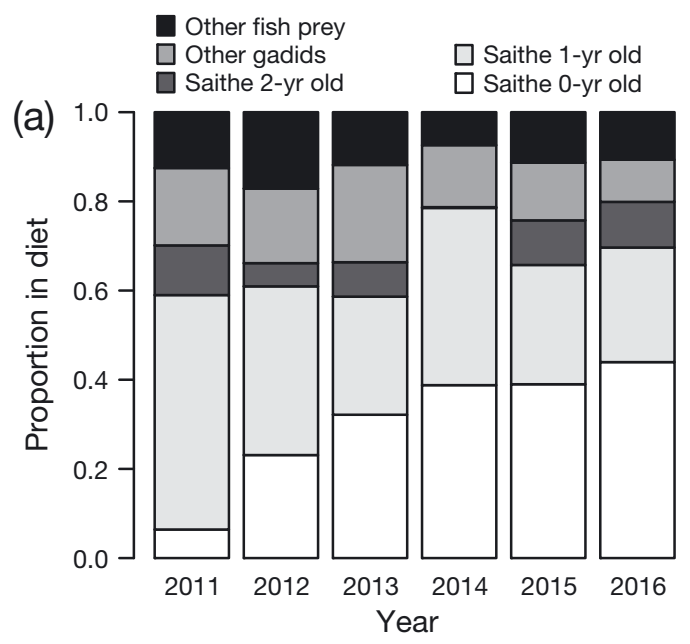

linear mixed models (one for each response variable) where year was included as a fixed factor (to estimate means $\mathrm{yr}^{-1}$ ). Sex of the bird and the $5 \mathrm{~d}$ period in which the trip was conducted was accounted for by including these as random intercepts.

To extend the analyses of foraging trips in relation to diet to an annual scale, we further analysed the annual means of trip metrics, estimated in the foraging activity variable, in relation to the annual diet composition in the population using simple linear models.

\section{RESULTS}

\subsection{Breeding population size and success}

During the study period, the colony was comprised of 1564-2570 pairs of shags $(\bar{x} \pm \mathrm{SD}=2112 \pm 399)$, and breeding success varied between 0.13 and 1.63 chicks nest $^{-1}(\bar{x} \pm \mathrm{SD}=0.86 \pm 0.51$; Table S1). Breeding success was highly correlated with breeding population size $\left(\beta \pm \mathrm{SE}=0.002 \pm 0.0002, \mathrm{R}^{2}=0.92, \mathrm{p}=\right.$ $0.002)$. Given this strong correlation we only used breeding success in the analyses.

\subsection{Diet and breeding success}

Overall, saithe was the most common prey species for shags at Sklinna during the study period (annual $\bar{X}=73 \%$, range $=66-80 \%$ ), followed by other gadids $(\bar{x}=15 \%$, range $=9-22 \%)$ and other fish prey $(\bar{x}=$ $12 \%$, range $=7-17 \%$; Fig. 2a). There were both seasonal and annual differences in the occurrence of the

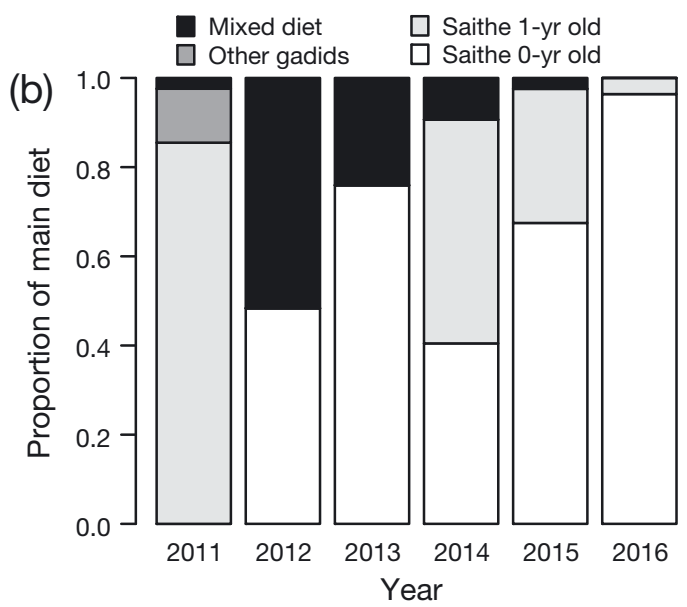

Fig. 2. Distribution of different prey classes in the diet of European shag based on data from (a) the whole season each year and (b) the main diet during the analysed foraging trips. Note that (b) is based on prey groups representing $>40 \%$ of the diet within 5 d periods concurrent with the time of the trips. That is, when e.g. 1 yr old saithe did not occur with this proportion (as in 2012 and 2013), it is included in the mixed group 
different prey types (Fig. S3 in the Supplement). Since the data from diet sampling was allocated to the same $5 \mathrm{~d}$ periods as GPS- and TDR-data, the prey data set used in the trip analyses differed somewhat from the one comprising the whole season (Fig. 2b). The largest difference between the prey data set for the whole season and the main diet data set linked to GPS- and TDR-data was the lack of 1 yr old saithe as the main diet group (i.e. $>40 \%$ of the diet biomass) in the diet for birds in 2012 and 2013. Generally, there was a seasonal increase in the proportion of 0 yr old saithe in the diet, whereas the proportion of $1 \mathrm{yr}$ olds decreased (Fig. S3). Thus, the lack of 1 yr old saithe as the dominating prey group in these years might be attributed to late timing of breeding (Table S1 in the Supplement).

The proportion of other prey fish species (excluding saithe and other gadids) never reached more than $18 \%$ of the diet, but were nonetheless nega-
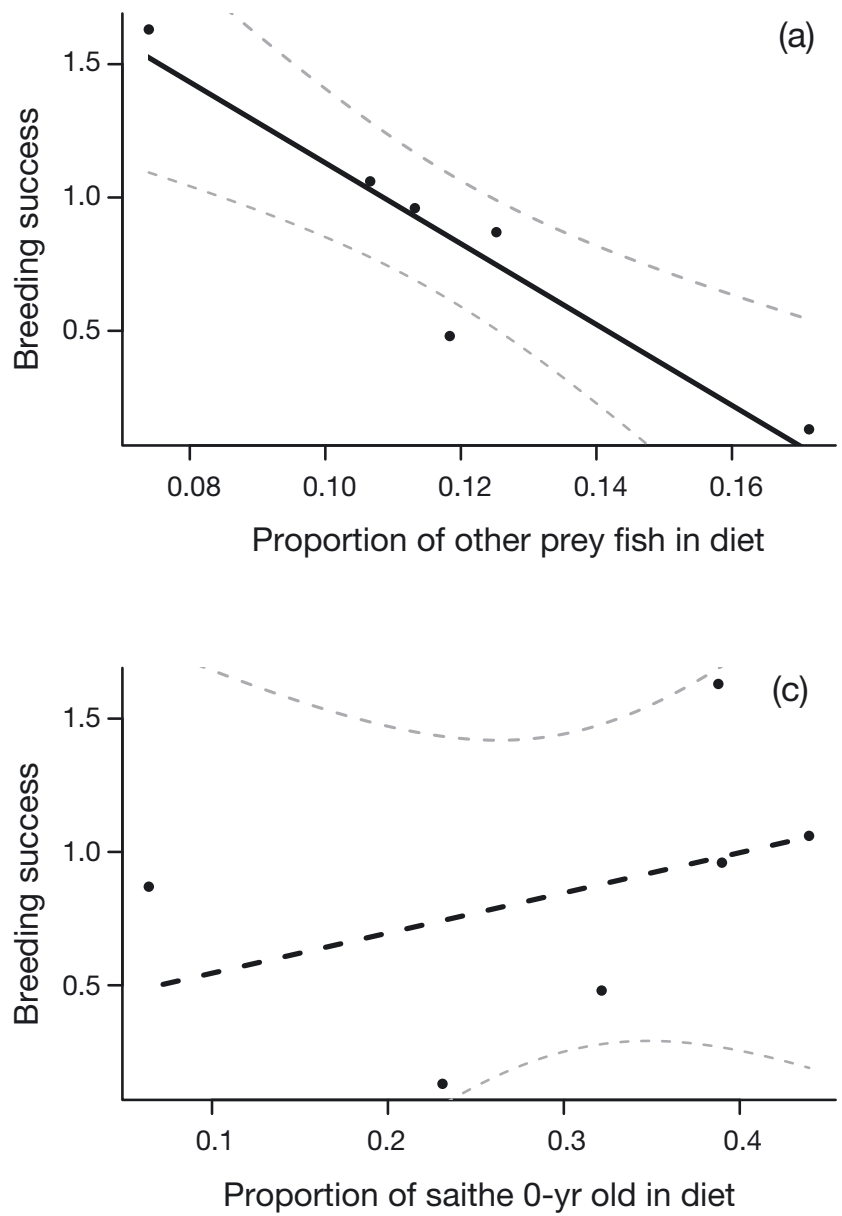

tively correlated with breeding success $(\beta \pm \mathrm{SE}=$ $-15.2 \pm 2.94, R^{2}=0.84, p=0.007$; Fig. 3$)$. There was a positive correlation between the total proportion of saithe in the diet and breeding success $(\beta \pm \mathrm{SE}=7.3$ $\pm 2.13, \mathrm{R}^{2}=0.68, \mathrm{p}=0.03, \mathrm{n}=6$; Fig. 3), whereas the proportion of 0 and $1 \mathrm{yr}$ old saithe in the diet separately $\left(\mathrm{R}^{2}=-0.04, \mathrm{p}=0.4\right.$, and $\mathrm{R}^{2}=-0.24, \mathrm{p}=0.9$, respectively), and the proportion of 'other gadids' (cod and codfish; $\mathrm{R}^{2}=-0.12, \mathrm{p}=0.3$ ) did not influence breeding success.

\subsection{Seasonal and annual differences in diet and trip characteristics}

Trip distance was best explained by the full model (AIC weight $=0.42$ ) while chick age was excluded in the top ranked model of total dive depth (AIC weight $=0.75$; Table 1 ; see also Table S2 in the Sup-

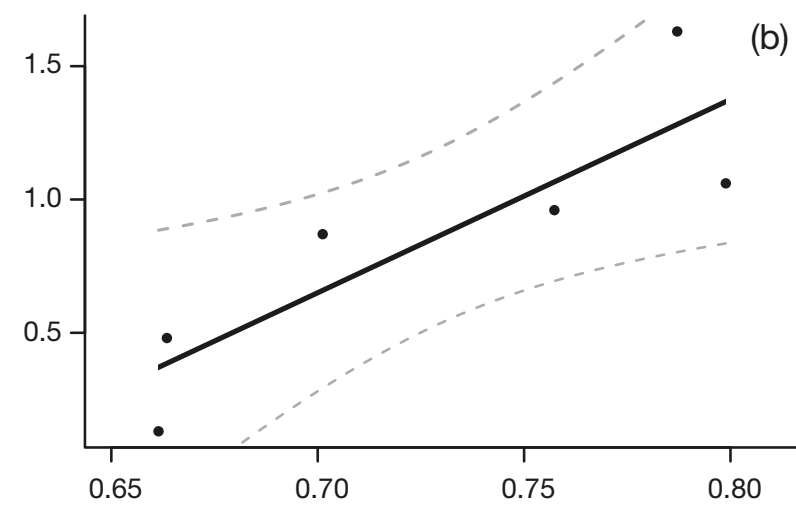

Proportion of saithe in diet

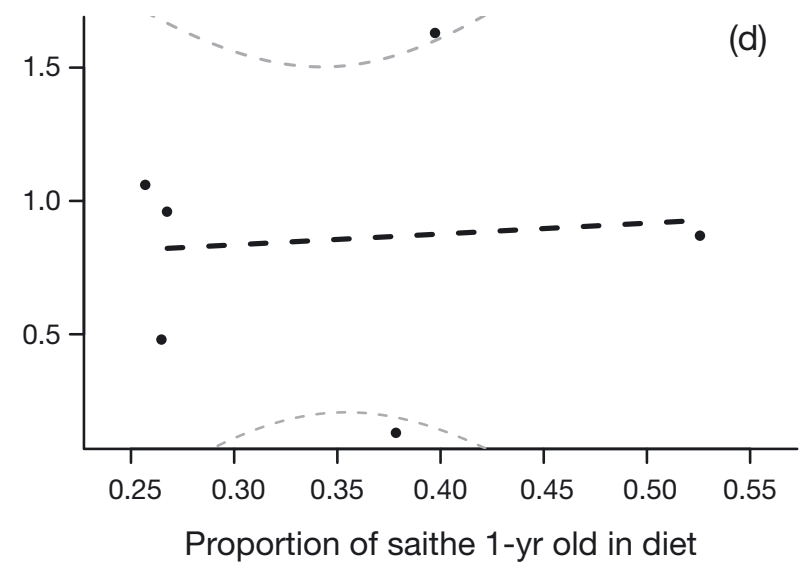

Fig. 3. Breeding success (no. of chicks $>20 \mathrm{~d} /$ no. control nests) in European shags in relation to proportion of different classes of prey in the diet: (a) other prey fish species (b) all age groups of saithe pooled (total saithe), (c) 0 yr old saithe and (d) 1 yr old saithe. Dots: raw data; lines: fitted values (black) with confidence intervals (grey). Significant correlations are represented by solid lines 
plement). Main diet (species consisting $>40 \%$ of the diet within $5 \mathrm{~d}$ periods) had no clear influence on distance travelled (Fig. 4a) but affected total dive depth during a trip (Table S3 in the Supplement). Total dive depth was not influenced by age class of saithe but was greater during trips in time periods where the main diet consisted of other gadids (Table S3, Fig. 4c). However, this should be considered with some caution as sample size for 'other gadids' was only 2. In 2014, a year with high population size (2570 pairs) and breeding success (1.63 chicks nest $^{-1}$; Table S1), and a high proportion of saithe in the diet (Fig. 2a), shags both flew shorter distances and dived less during a trip than most other years (Fig. 4b,d, Table S3). In 2012, a year with low population size
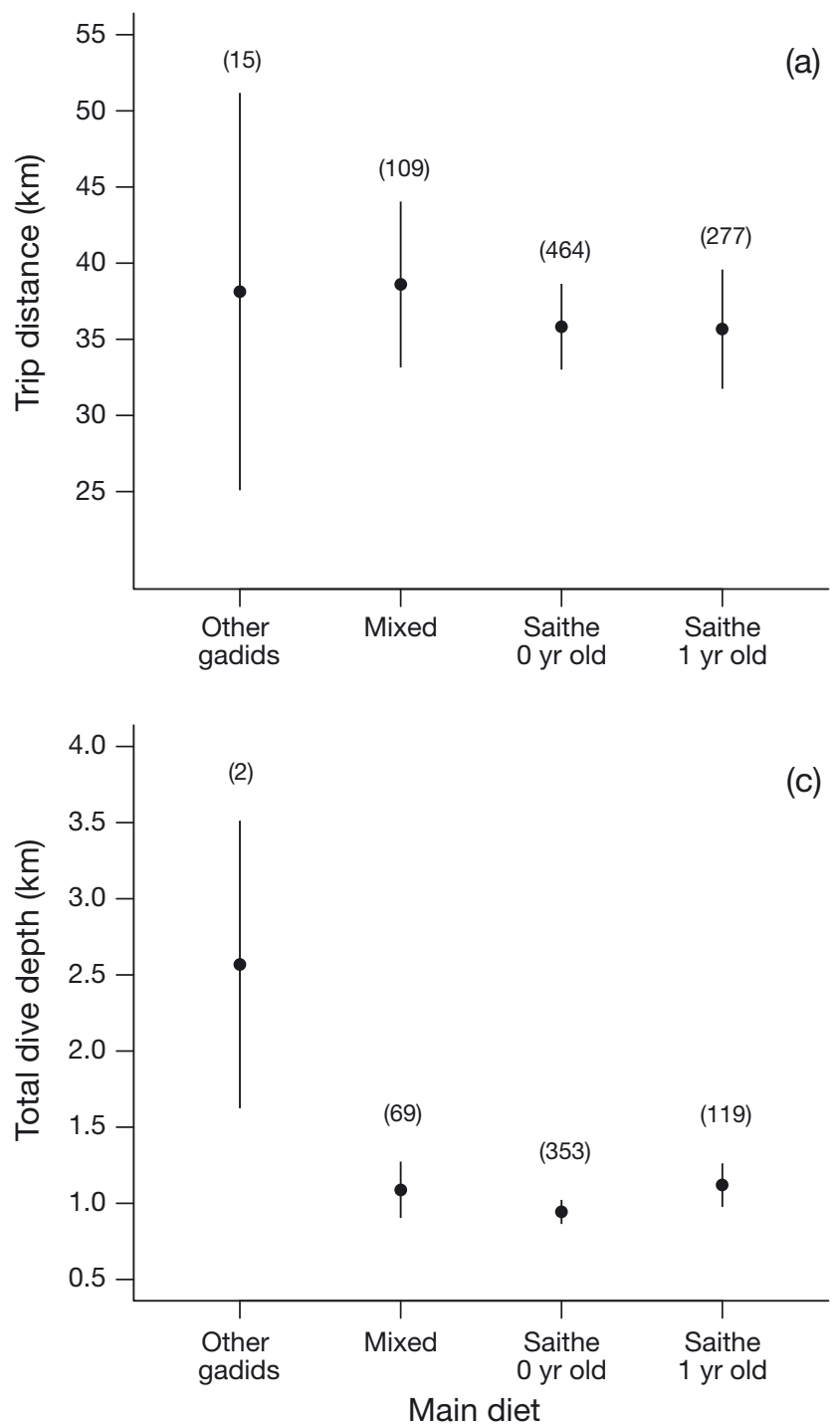

(1564 pairs) and low breeding success (0.13 chicks nest $^{-1}$; Table S1), shags had, in particular, a high diving activity (Table S3, Fig. 4d) but also long total trip distance travelled (Fig. 4b), especially compared to the top year, 2014. There was no clear difference in trip distance between male and female shags, but males dived more than females (Table 1). Trip distances decreased with increasing age of the chicks (Table 1, Fig. S4 in the Supplement).

Annual means of trip distance and total dive depth were not influenced by the proportion of either 0 or 1 yr old saithe in the diet $\left(R^{2}<0.08, p>0.3\right.$; Fig. S5c-f in the Supplement). However, for all saithe yearclasses combined, mean trip distance decreased with increasing proportions of saithe $(\beta \pm \mathrm{SE}=-113.3 \pm 38.2$,
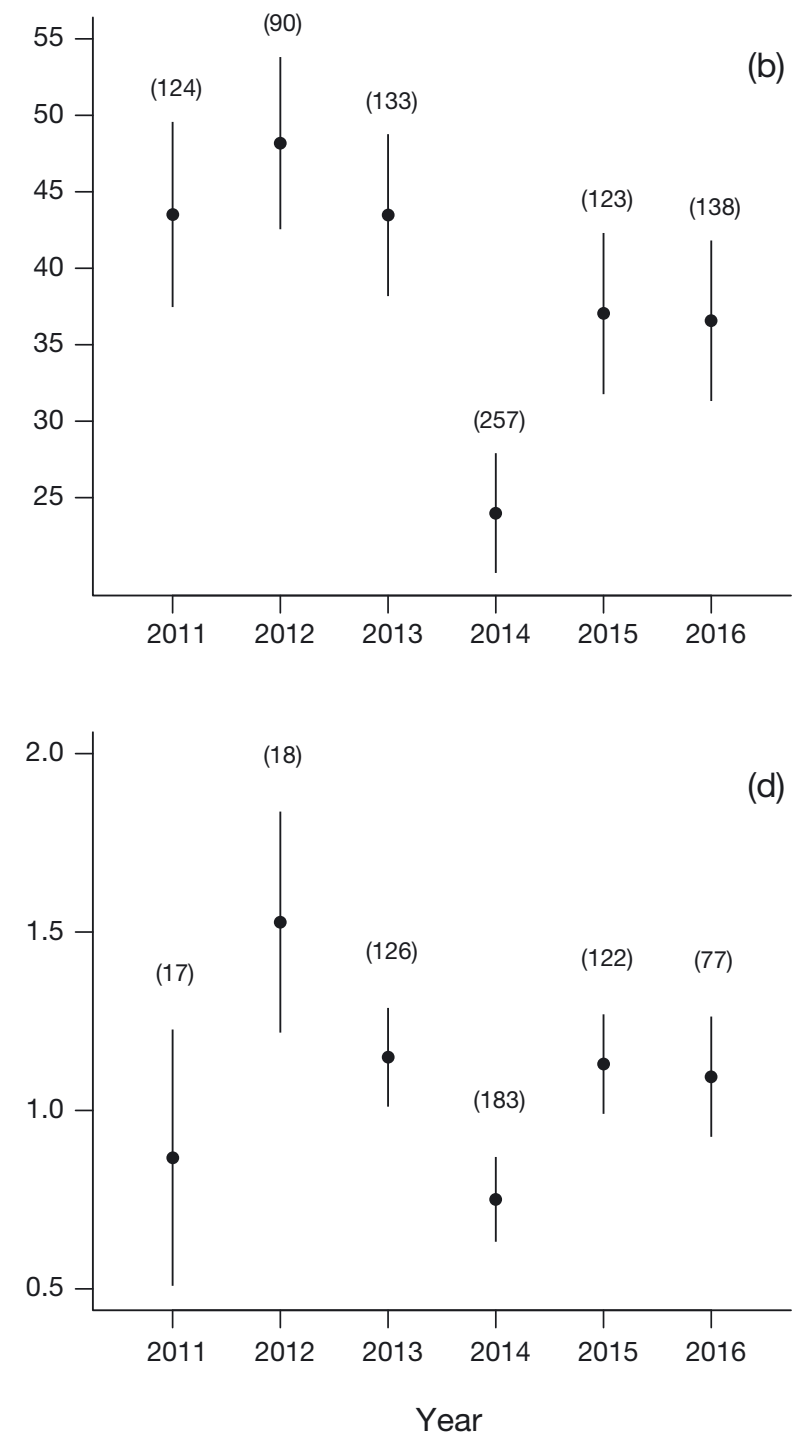

Fig. 4. (a,b) Trip distance and $(\mathrm{c}, \mathrm{d})$ total dive depth during foraging trips of European shags in relation to main diet and year, represented as estimated means with $\mathrm{SE}$ where the other variables were kept at their typical value. Sample size (no. of trips) are shown in brackets 
Table 1. Top ranked linear models of the influence of annual variation, diet, chick age and sex on the distance travelled $(\mathrm{km})$ and the total dive depth $(\mathrm{km})$ by European shag at Sklinna, Norway in 2011-2016. Note: reference groups are year $=2011$, diet $=$ other gadids, sex $=$ male. Individual bird was included as a random intercept in both models

\begin{tabular}{|lrrrr|} 
& \multicolumn{2}{c}{ Trip distance } & \multicolumn{2}{c|}{ Total dive depth } \\
& $\beta$ & SE & \multicolumn{1}{c}{$\beta$} & SE \\
\hline Intercept & 49.68 & 6.25 & 2.53 & 0.45 \\
Year 2012 & 4.67 & 4.57 & 0.66 & 0.25 \\
Year 2013 & -0.04 & 4.50 & 0.28 & 0.20 \\
Year 2014 & -19.52 & 3.55 & -0.12 & 0.19 \\
Year 2015 & -6.48 & 4.08 & 0.26 & 0.19 \\
Year 2016 & -6.95 & 4.45 & 0.23 & 0.21 \\
Diet mixed & 0.46 & 7.37 & -1.48 & 0.49 \\
Diet saithe 0 yr & -2.31 & 7.00 & -1.63 & 0.48 \\
Diet saithe 1 yr & -2.47 & 6.46 & -1.45 & 0.48 \\
Chick age & -0.32 & 0.14 & & \\
Sex (female) & -1.24 & 1.96 & -0.22 & 0.07 \\
Marginal $\mathrm{R}^{2}$ & 0.18 & & 0.16 & \\
Conditional $\mathrm{R}^{2}$ & 0.50 & & 0.40 & \\
& & & & \\
\hline
\end{tabular}

$\mathrm{R}^{2}=0.61, \mathrm{p}=0.04, \mathrm{n}=6$; Fig. S5b), indicating that the prey species rather than the switch between age classes of saithe influenced how far the shags needed to fly. Annual variation in total dive depth was less related to the proportion of saithe in the diet $(\beta \pm \mathrm{SE}=$ $-2.6 \pm 1.3, R^{2}=0.39, p=0.1$; Fig. S5a). Both mean total dive depth and trip distance were strongly and positively correlated with the proportion of other fish species in the diet (dive depth: $\beta \pm \mathrm{SE}=7.0 \pm 0.30$, $\mathrm{R}^{2}=0.99, \mathrm{p}<0.0001$; trip distance: $\beta \pm \mathrm{SE}=244.5 \pm$ 50.12, $R^{2}=0.82, p=0.008$; Fig. S5g,h).
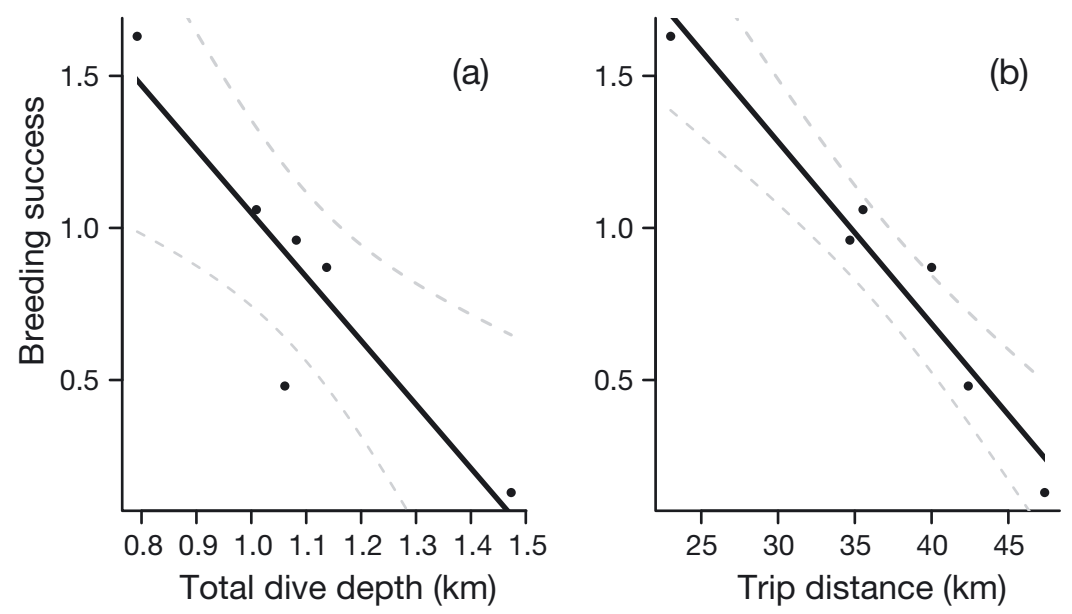

Fig. 5. Breeding success (no. of chicks $>20$ d / no. control nests) in European shags in relation to (a) annual mean total dive depth and (b) annual mean distance travelled during foraging trips. Dots: raw data; lines: fitted values (black) with confidence interval (grey)

\subsection{Breeding success and trip characteristics}

Breeding success was negatively influenced by annual means of trip distance $(\beta \pm \mathrm{SE}=-0.06 \pm 0.007$, $\left.\mathrm{R}^{2}=0.93, \mathrm{p}=0.001\right)$. Accumulated dive depths during a trip also influenced breeding success in a negative way $\left(\beta \pm \mathrm{SE}=-2.1 \pm 0.5, \mathrm{R}^{2}=0.77, \mathrm{p}=0.01\right)$, indicating that when the shags worked harder to find prey of relevant amount and quality, breeding success was lower (Fig. 5).

\section{DISCUSSION}

Our study clearly demonstrated that breeding success of shags at Sklinna was positively correlated with the breeding population size. This suggests that when foraging conditions around the colony were favourable, many pairs bred and had high breeding success. We also found a close and positive correlation between breeding success and the total occurrence of saithe in the diet. Moreover, mean trip distances decreased with increasing proportions of saithe, whereas the proportions of the individual age-classes of saithe in the diet did not explain any variation in breeding success. Shag breeding success was negatively influenced by annual means of trip distance and accumulated diving depths, indicating that when the adults had to work hard to find enough prey, they produced fewer chicks. These feeding conditions also negatively impacted breeding numbers, where low numbers were observed in years with increased feeding effort.

The findings of the overall importance of saithe in shag diet in this study corroborates previous studies at the same site (Hillersøy \& Lorentsen 2012, Bustnes et al. 2013, Lorentsen et al. 2015). Interestingly, the proportion of other prey fish species (excluding saithe and other gadids) was generally low, but nonetheless had a significant negative effect on breeding success. This further emphasizes the significance of saithe as the most important prey species for shags in this colony. Close correlations between prey availability and population size (Erikstad et al. 2013, Elliott et al. 2015, Velarde et al. 2015, Sandvik et al. 2016) and breeding success (Frederiksen et al. 2004, Cury et al. 2011) have been found in many seabird studies. In this context, 
this study provides novel insight by combining a multi-year data set on diet and foraging behavior and concurrent data on reproductive success and breeding numbers.

Main diet did not influence the distance travelled during individual foraging trips. However, on an annual basis, trip distance did decrease with the proportions of saithe in the diet and both of these factors were positively correlated with breeding success. This might suggest that foraging location and profitability may be more important determinants of distance than exact prey composition. However, without data on prey capture rates and profitability of prey abundance, the mechanisms are difficult to identify and quantify. Shags tended to dive more on individual foraging trips when proportions of saithe in the diet were low. Due to a general low inclusion of other fish species in the shags' diet, these prey species were mostly included in the mixed diet group, and as this diet group also includes saithe in smaller proportions, this could mask the fine-scale influence of other prey species on foraging metrics. On an annual basis, however, we did observe an increase in both foraging range and diving intensity with increasing proportion of prey species other than gadids. These findings are different from those at the Isle of May, where Bogdanova et al. (2014) did not find a correlation between annual foraging ranges and diet composition in shags. This may be related to restricted distribution of sandeel around the Isle of May. Thus, knowledge of the distribution of habitats for preferred prey species in different study systems is required to interpret the significance of the foraging patterns observed.

Breeding seabirds have at least 2 different behavioural options when prey availability is low: increasing their foraging ranges (e.g. Monaghan et al. 1994, Garthe et al. 2011) or spending more time foraging near the colony, at the expense of reduced resting time in the foraging areas or at the nest (e.g. Litzow \& Piatt 2003, Lescroël \& Bost 2005). At Sklinna, the foraging habitats available for the main prey species (saithe) of shags are patchily distributed, and the shags therefore mainly foraged either within $4 \mathrm{~km}$ of the colony (i.e. within the Sklinna archipelago) or more than $15 \mathrm{~km}$ away from the colony (ChristensenDalsgaard et al. 2017). As breeding population size declined with decreased breeding success, shags at Sklinna most likely skipped breeding in years with poor foraging conditions, a phenomenon not uncommon in seabirds (e.g. Passuni et al. 2018). However, the shags that did initiate breeding in poorer years apparently had to increase their foraging ranges and utilized distant patches more than in years with high breeding success. When abundance of saithe was low the birds also had to spend more time diving in search for food, which is also energetically costly (e.g. Hicks et al. 2017).

Saithe spawn pelagically (e.g. Mehl 2015) and consequently there might be an influx of 0 yr old saithe into the shags' foraging areas as the breeding season progresses (cf. Howells et al. 2017). The extent of this influx varies among years (cf. Fig. S3 for Sklinna) and might, at least in some years, provide a significant influx of prey to depleted habitats. Thus, the finding that shags travelled shorter distances per trip as the chicks got older may be explained by an influx of $0 \mathrm{yr}$ old saithe to near-colony waters as the breeding season progressed. Prey influx was found to be an important factor regulating breeding success and foraging behavior in the inshore-feeding little penguin Eudyptula minor (Kowalczyk et al. 2015a,b).

This study is one of very few to combine the effects of foraging distribution, breeding population numbers, breeding success and diet composition during several years of variable prey abundance. Our study concentrated on a coastal seabird species with a short foraging range and provides new insight into the complex factors regulating numbers of breeding birds and breeding success in a coastal ecosystem with large annual variations in prey abundance. We provide knowledge for the management of coastal ecosystems, such as demonstrating the need to protect the complete foraging areas around the colonies in order to secure access to foraging grounds even in poor years when breeding birds may need to search for prey further away from the colony. This study emphasizes the importance of further research on the interplay between reproductive performance, diet and foraging metrics of coastal seabirds as their habitats are increasingly affected by anthropogenic impacts (e.g. Halpern et al. 2009). Generally, there is a lack of multi-year studies combining these variables in a manner that can be used to predict changes in foraging areas related to (years of) low food abundance.

Acknowledgements. We are indebted to all the field assistants who participated during the fieldwork at Sklinna, and to Grethe Hillersøy who analysed the pellet samples. The work in the colony was approved by the Norwegian Environment Agency, and the county governor of NordTrøndelag. Capture and handling of birds were approved by the Norwegian Environment Agency and the Norwegian Animal Research Authority. We are indebted to the Norwegian Coastal Administration for allowing us to use the Sklinna lighthouse facilities as a field station. The work at 
Sklinna is part of the SEAPOP program (www.seapop.no), which is financed by the Norwegian Ministry of Climate and Environment via the Norwegian Environment Agency, the Norwegian Ministry of Petroleum and Energy via the Norwegian Research council and the Norwegian Oil and Gas Association.

\section{LITERATURE CITED}

Anker-Nilssen T, Aarvak T (2006) Long-term studies of seabirds in the municipality of Røst, Nordland. Results with focus on 2004 and 2005. NINA Report 133. Norwegian Institute for Nature Research, Trondheim

Ashbrook K, Wanless S, Harris MP, Hamer KC (2010) Impacts of poor food availability on positive density dependence in a highly colonial seabird. Proc R Soc B 277:2355-2360

Ashmole NP (1963) The regulation of numbers of tropical oceanic birds. Ibis 103b:458-473

Barton K (2016) MuMIn: multi-model inference. R package version 1.15.6. https://CRAN.R-project.org/package= MuMIn

*Bates D, Maechler M, Bolker B, Walker S (2015) Fitting linear mixed-effects models using lme4. J Stat Softw 67: $1-48$

* Bogdanova MI, Wanless S, Harris MP, Lindström J and others (2014) Among-year and within-population variation in foraging distribution of European shags Phalacrocorax aristotelis over two decades: implication for marine spatial planning. Biol Conserv 170:292-299

Burke CM, Davoren GK (2009) The foraging decisions of a central place foraging seabird in response to fluctuations in local prey conditions. J Zool 278:354-361

Burnham KP, Anderson DR (2002) Model selection and multimodel inference: a practical information-theoretic approach. Springer-Verlag, New York, NY

* Bustnes JO, Anker-Nilssen T, Erikstad KE, Lorentsen SH, Systad GH (2013) Changes in the Norwegian breeding population of European shag correlate with forage fish and climate. Mar Ecol Prog Ser 489:235-244

* Christensen-Dalsgaard S, Mattisson J, Bekkby T, Gundersen H, May R, Rinde E, Lorentsen SH (2017) Habitat selection of foraging chick-rearing European shags in contrasting marine environments. Mar Biol 164:196

* Christensen-Dalsgaard S, May R, Lorentsen SH (2018) Taking a trip to the shelf: Behavioural decisions are mediated by the proximity to foraging habitats in the blacklegged kittiwake. Ecol Evol 8:866-878

Cramp S, Simmons KEL (1977) The birds of the Western Palearctic, Vol 1. Oxford University Press, Oxford

* Croxall JP, Butchart SHM, Lascelles B, Stattersfield AJ, Sullivan B, Symes A, Taylor P (2012) Seabird conservation status, threats and priority actions: a global assessment. Bird Conserv Int 22:1-34

* Cury PM, Boyd IL, Bonhommeau S, Anker-Nilssen T and others (2011) Global seabird response to forage fish depletion-one-third for the birds. Science 334:1703-1706

Davies RD, Wanless S, Lewis S, Hamer KC (2013) Densitydependent foraging and colony growth in a pelagic seabird species under varying environmental conditions. Mar Ecol Prog Ser 485:287-294

* Elliott KH, Woo KJ, Gaston AJ, Benvenuti S, Dall'Antonia L, Davoren GK (2009) Central-place foraging in an Arctic seabird provides evidence for Storer-Ashmole's Halo.
Auk 126:613-625

*Elliott ML, Bradley RW, Robinette DP, Jahncke J (2015) Changes in forage fish community indicated by the diet of the Brandt's cormorant (Phalacrocorax penicillatus) in the central California Current. J Mar Syst 146:50-58

E Erikstad KE, Reiertsen TK, Barrett RT, Vikebø F, Sandvik H (2013) Seabird-fish interactions: the fall and rise of a common guillemot Uria aalge population. Mar Ecol Prog Ser 475:267-276

FFrederiksen M, Harris MP, Daunt F, Rothery P, Wanless S (2004) Scale-dependent climate signals drive breeding phenology of three seabird species. Glob Change Biol 10:1214-1221

Frederiksen M, Anker-Nilsen T, Beaugrands G, Wanless S (2013) Climate, copepods and seabirds in the boreal Northeast Atlantic-current state and future outlook. Glob Change Biol 19:364-372

*Garthe S, Montevecchi WA, Davoren G (2011) Inter-annual changes in prey fields trigger different foraging tactics in a large marine predator. Limnol Oceanogr 56:802-812

*Halpern BS, Ebert CM, Kappel CV, Madin EMP and others (2009) Global priority areas for incorporating land-sea connections in marine conservation. Conserv Lett 2: 189-196

*Hamer KC, Monaghan P, Uttley JD, Walton P, Burns MD (1993) The influence of food supply on the breeding ecology of Kittiwakes Rissa tridactyla in Shetland. Ibis 135: 255-263

*Hamer KC, Humphreys EM, Garthe S, Hennicke J and others (2007) Annual variation in diets, feeding locations and foraging behaviour of gannets in the North Sea: flexibility, consistency and constraint. Mar Ecol Prog Ser 338:295-305

Härkönen TJ (1986) Guide to the otoliths of the bony fishes of the northeast Atlantic. Danbiu ApS, Copenhagen

KHicks O, Burthe S, Daunt F, Butler A, Bishop C, Green JA (2017) Validating accelerometry estimates of energy expenditure across behaviours using heart rate data in a free-living seabird. J Exp Biol 220:1875-1881

* Hillersøy G, Lorentsen SH (2012) Annual variation in the diet of breeding European shag (Phalacrocorax Aristotelis) in central Norway. Waterbirds 35:420-429

*Howells RJ, Burthe SJ, Green JA, Harris MP and others (2017) From days to decades: short- and long-term variation in environmental conditions affect offspring diet composition of a marine top predator. Mar Ecol Prog Ser 583:227-242

Jobling M, Breiby A (1986) The use and abuse of fish otoliths in studies of feeding habits of marine piscivores. Sarsia 71:265-274

Kowalczyk ND, Chiaradia A, Preston TJ, Reina RD (2015a) Fine-scale dietary changes between the breeding and non-breeding diet of a resident seabird. R Soc Open Sci 2:140291

* Kowalczyk ND, Reina RD, Preston TJ, Chiaradia A (2015b) Environmental variability drives shifts in foraging success of an inshore seabird. Oecologia 178:967-979

* Lenth RV (2016) Least-squares means: the R package lsmeans. J Stat Softw 69:1-33

* Lescroël A, Bost CA (2005) Foraging under contrasting oceanographic conditions: the gentoo penguin at Kerguelen Archipelago. Mar Ecol Prog Ser 302:245-261

Lewis S, Sherratt TN, Hamer KC, Wanless S (2001) Evidence of intra-specific competition for food in a pelagic seabird. Nature 412:816-819 
Lewis S, Grémillet D, Daunt F, Ryan PG, Crawford RJ, Wanless S (2006) Using behavioural and state variables to identify proximate causes of population change in a seabird. Oecologia 147:606-614

Lewison R, Oro D, Godley BJ, Underhill L and others (2012) Research priorities for seabirds: improving conservation and management in the 21st century. Endang Species Res 17:93-121

Litzow MA, Piatt JF (2003) Variance in prey abundance influences time budgets of breeding seabirds: evidence from pigeon guillemots Cepphus columba. J Avian Biol 34:54-64

Lorentsen SH, Anker-Nilssen T, Erikstad KE, Røv N (2015) Forage fish abundance is a predictor of timing of breeding and hatching brood size in a coastal seabird. Mar Ecol Prog Ser 519:209-220

Lorentsen SH, Anker-Nilssen T, Erikstad KE (2018) Seabirds as guides for fisheries management: European shag Phalacrocorax aristotelis diet as indicator of saithe Pollachius virens recruitment. Mar Ecol Prog Ser 586:193-201

Mehl S (2015) Nordaustarktisk sei. In: Bakketeig IE, Gjøsæter H, Hauge M, Sunnset BH, Toft KØ (eds) Havforskningsrapporten 2015. Havforskningsinstituttet, Bergen, p 184

Michelot C, Pinaud D, Fortin M, Maes P, Callard B, Leicher M, Barbraud C (2017) Seasonal variation in coastal marine habitat use by the European shag: insights from fine scale habitat selection modeling and diet. Deep-Sea Res II 141:224-236

Monaghan P, Walton P, Wanless S, Uttley JD, Burns MD (1994) Effects of prey abundance on the foraging behavior, diving efficiency and time allocation of breeding guillemots Uria aalge. Ibis 136:214-222

Orians GH, Pearson NE (1979) On the theory of central place foraging. In: Horn DJ, Mitchell RD, Stairs GR (eds) Analysis of ecological systems. Ohio State University Press, Columbus, OH, p 155-177

Passuni G, Barbraud C, Chaigneau A, Bertrand A and others (2018) Long-term changes in the breeding seasonality of Peruvian seabirds and regime shifts in the Northern Humboldt Current System. Mar Ecol Prog Ser 597: 231-242

Pettex E, Lorentsen SH, Grémillet D, Gimenez O and others (2012) Multi-scale foraging variability in northern gannet (Morus bassanus) fuels potential foraging plasticity.

Editorial responsibility: Kyle Elliott,

Sainte-Anne-de-Bellevue, Québec, Canada
Mar Biol 159:2743-2756

* Pichegru L, Ryan PG, van der Lingen CD, Coetzee J, RopertCoudert Y, Grémillet D (2007) Foraging behaviour and energetics of Cape gannets Morus capensis feeding on live prey and fishery discards in the Benguela upwelling system. Mar Ecol Prog Ser 350:127-136

* Poloczanska ES, Brown CJ, Sydeman WJ, Kiessling W and others (2013) Global imprint of climate change on marine life. Nat Clim Chang 3:919-925

*Ponchon A, Grémillet D, Christensen-Dalsgaard S, Erikstad KE and others (2014) When things go wrong: intra-season dynamics of breeding failure in a seabird. Ecosphere $5: 4$

* Quintana F, Wilson R, Dell'Arciprete P, Shepard E, Laich AG (2011) Women from Venus, men from Mars: inter-sex foraging differences in the imperial cormorant Phalacrocorax atriceps a colonial seabird. Oikos 120:350-358

R Development Core Team (2016) R: a language and environment for statistical computing. R Foundation for Statistical Computing, Vienna

Riou S, Gray CM, Brooke MdL, Quillfeldt P, Masello JF, Perrins C, Hamer K (2011) Recent impacts of anthropogenic climate change on a higher marine predator in western Britain. Mar Ecol Prog Ser 422:105-112

Sandvik H, Barrett RT, Erikstad KE, Myksvoll MS and others (2016) Modelled drift patterns of fish larvae link coastal morphology to seabird colony distribution. Nat Commun 7:11599

Shealer DA (2002) Foraging behavior and food of seabirds. In: Schreiber EA, Burger J (eds) Biology of marine birds. CRC Press, Boca Raton, FL, p 137-178

*Vandenabeele SP, Shepard EL, Grogan A, Wilson RP (2012) When three per cent may not be three per cent; deviceequipped seabirds experience variable flight constraints. Mar Biol 159:1-14

V Velarde E, Ezcurra E, Anderson DW (2015) Seabird diet predicts following-season commercial catch of Gulf of California Pacific sardine and northern anchovy. J Mar Syst 146:82-88

Walsh PM, Halley DJ, Harris MP, del Nevo A, Sim IMW, Tasker ML (1995) Seabird monitoring handbook for Britain and Ireland. JNCC/RSPB/ITE/Seabird Group, Peterborough

Wanless S, Harris M (1997) Shag. Birds of the Western Palearctic Update 1:3-13

Submitted: February 16, 2018; Accepted: March 27, 2019

Proofs received from author(s): May 10, 2019 